
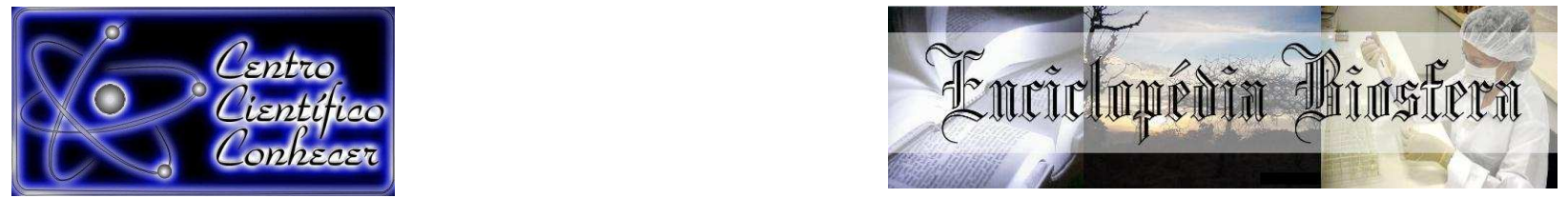

\title{
CARACTERIZAÇÃO FENOLÓGICA DE TRÊS ESPÉCIES FLORESTAIS EM ECOSSISTEMA DE TERRA FIRME, AMAPÁ, BRASIL
}

\author{
João da Luz Freitas ${ }^{1}$, Adriano Castelo dos Santos ${ }^{2}$, Francisco de Oliveira Cruz \\ Junior ${ }^{1}$, Maurício Alves Sardinha ${ }^{3}$ \\ ${ }^{1}$ Instituto de Pesquisas Científicas e Tecnológicas do Estado do Amapá \\ (jfreitas.ap@bol.com.br). \\ 2 Instituto Estadual de Florestas do Amapá - IEF. \\ ${ }^{3}$ Discente do Curso de Pós-Graduação da Universidade Federal do Amapá.
}

Recebido em: 03/10/2016 - Aprovado em: 21/11/2016 - Publicado em: 05/12/2016 DOI: 10.18677/EnciBio_2016B_020

\begin{abstract}
RESUMO
O objetivo deste trabalho foi obter informações referentes à fenologia reprodutiva de três espécies florestais: Carapa guianensis Aubl., Caryocar villosum (Aubl.) Pers. e Virola melinonii (Benoist) A.C.Sm., em floresta de terra firme. O estudo foi desenvolvido no município de Porto Grande, Amapá. Foram selecionadas 10 matrizes de cada espécie e observadas a floração, frutificação e mudança foliar para cada árvore por um período de 28 meses. A floração das espécies $V$. melinonii, $C$. villosum ocorreu durante o período de estiagem. A época mais adequada para a coleta de frutos de $C$. guianensis e $C$. villosum é durante os meses de fevereiro a junho na área de estudo. A espécie $V$. melinonii apresentou o evento frutificação durante a fase de estiagem.
\end{abstract}

PALAVRAS-CHAVE: Amazônia, Fenofase, Manejo florestal.

\section{CHARACTERIZATION PHENOLOGICAL OF THREE FOREST SPECIES IN ECOSYSTEM OF UP LAND, AMAPÁ, BRAZIL}

\begin{abstract}
The objective of this work was to obtain information regarding the reproductive phenology of three forest species: Carapa guianensis Aubl., Caryocar villosum (Aubl.) Pers. and Virola melinonii (Benoist) A.C.Sm., in up land forest. The study was developed in the municipal of Porto Grande, Amapa. 10 ideotypes of each species were selected and observed the floration, fructification and foliage change for each tree for a period of 28 months. The floration of the species V. melinonii, C. villosum happened during the time of smaller precipitation pluviometric. The most appropriate period for the collection of fruits of $\mathrm{C}$. guianensis and $\mathrm{C}$. villosum is during the months of February to June in the study area. The species $\mathrm{V}$. melinonii presented the event fructification during the drought period.
\end{abstract}

KEYWORDS: Amazon, Phenophase, forest Management.

\section{INTRODUÇÃO}

As florestas tropicais úmidas são caracterizadas, especialmente, pela alta diversidade de espécies com indivíduos de diferentes idades e tamanhos e características ecofisiológicas distintas, favorecendo grande quantidade e variedade 
de produtos madeireiros e não madeireiros (PINHEIRO, 2014). A região amazônica apresenta uma série contínua de formações vegetais que são bem distintas floristicamente devido aos variados fatores ambientais que promovem diversas associações entre os componentes bióticos de cada ecossistema (KUNZ et al., 2009).

O conhecimento dos padrões fenológicos e da biologia floral, a determinação do papel dos vetores de fluxo de pólen, além do entendimento do sistema reprodutivo, são pontos fundamentais para a compreensão da biologia reprodutiva da espécie (VIEIRA et al., 2012). Os fatores que influenciam os ritmos fenológicos podem ser divididos em duas categorias: bióticos e abióticos (LIEBSCH \& MIKICH, 2009). Alguns autores associam os períodos de floração e frutificação a fatores abióticos (OLIVEIRA \& PIEDADE, 2002). Os eventos fenológicos estão geralmente sujeitos a variações ambientais relacionadas ao clima (ATHAYDE et al., 2009).

A fenologia pode ser definida como o estudo da ocorrência de eventos vegetativos e reprodutivos das plantas no decorrer do ano e sua relação com fatores ambientais e bióticos (MISSAGIA et al., 2014). Esses estudos sobre fenologia abordam os diferentes eventos biológicos repetitivos que ocorrem durante o ciclo de vida das plantas (florescimento, frutificação, brotamento, queda foliar e germinação) e as causas de sua ocorrência (NEVES et al., 2010).

A demanda por produtos não madeireiros oriundos das florestas de terra firme têm aumentado consideravelmente a pressão sobre algumas espécies na região amazônica. A Carapa guianensis Aubl. é comumente chamada de andirobeira e é encontrada com abundância em toda a Bacia amazônica e seus afluentes, principalmente em regiões de Florestas de Baixo, Igapó e Várzeas, podendo ocorrer em florestas de terra firme (FERRAZ et al., 2002). O óleo da semente de andiroba possui importantes propriedades medicinais (FUNASAKI et al., 2016) e pode ser vendido em pequena escala para mercados local/regional e em grande escala para o mercado nacional e internacional. No mercado local/regional, o óleo é vendido em pequenas quantidades em garrafas de plástico por $R \$ 80,00$ o litro, nos mercados locais de Santarém/Pará (SIST et al., 2014). A exploração extrativista é cada vez mais promissora e inevitável, e pode ser futuramente mais intensificada (ABREU et al., 2014).

A espécie Virola melinonii, família Myristicaceae, é conhecida vulgarmente como ucuúba-da-terra-firme. Entre as espécies da família Myristicaceae, o gênero Virola é o que apresenta a mais ampla distribuição geográfica. Concentra-se no continente americano e ocorre desde a Guatemala até a Bolívia, Peru, Venezuela e Brasil, predominando nas regiões tropicais. Os indivíduos deste gênero são lenhosos e variam de pequenos arbustos a enormes árvores de cerca de 40 metros de altura. São comumente utilizados como matéria prima para cosméticos e compostos medicinais (FUNASAKI et al., 2016).

O Caryocar villosum é uma espécie comum na Amazônia Central, sendo conhecida regionalmente como piquiá. $O$ fato de ser uma espécie emergente dificulta a realização de estudos de biologia floral, fundamentais para a conservação dessa espécie ameaçada pela fragmentação e o interesse comercial na madeira (MARTINS \& GRIBEL, 2007).

Conhecer a fenologia dessas espécies é importante para o correto manejo de produtos extraídos dessas árvores, épocas de colheita ideais e, principalmente, para a conservação e manutenção das espécies. Desta forma, este trabalho teve como objetivo principal a obtenção de informações referentes à fenologia reprodutiva de três espécies florestais: Carapa guianensis Aubl., Caryocar villosum (Aubl.) Pers. e 
Virola melinonii (Benoist) A. C. Sm. em floresta de terra firme no Estado do Amapá. A relevância da pesquisa mostra sua importância uma vez que na área de estudo não há relatos de pesquisas semelhantes por longo período de monitoramento.

\section{MATERIAL E MÉTODOS}

Localização da área de estudo: $O$ estudo foi desenvolvido em uma área de floresta de terra firme, situada no município de Porto Grande, entre as coordenadas $00^{\circ} 51^{\prime} 59^{\prime \prime} \mathrm{N}$ e $051^{\circ} 24^{\prime}$ 02" W, localizado a sudest e do Estado do Amapá. Destacam-se na área do município de Porto Grande quatro fitofisionomias principais: Floresta Ombrófila Densa, Cerrado, Floresta de Várzea e Floresta Secundária (capoeira).

De acordo com Köppen, o clima da região é quente-úmido, do tipo Af, ocorrendo chuvas em todas as estações do ano. O período de julho a novembro registra os menores índices pluviométricos, sendo os meses de setembro, outubro e novembro os mais secos. A precipitação pluviométrica média anual na região é de $2100 \mathrm{~mm}$ (INMET, 2016).

Seleção das espécies: As espécies foram selecionadas por ordem de importância para a produção extrativa, principalmente medicinal e alimentação. As árvores foram selecionadas, dentro de categoria por ordem de ocorrência, segundo características fenotípicas desejáveis, tais como: boa conformação de fuste e copa, sanidade e com indicativo de realização do processo reprodutivo. Para cada espécie selecionou-se 10 matrizes que foram observadas fenologicamente.

As árvores selecionadas foram numeradas com fitas plásticas de identificação, devidamente identificadas pelo nome vernacular e então amarradas nas árvores com fio de nylon no ponto de medição do DAP, realizadas com pincel anatômico, e então foi procedida a coleta do material botânico para a correta identificação em nível de espécie, e família. Os dados monitorados foram tabulados e sistematizados através do programa Microsoft Office Excel 2010.

Monitoramento das fenofases: As observações fenológicas compreenderam 28 meses, de outubro de 1997 a janeiro de 2000, abrangendo os períodos de maior e menor precipitação pluviométrica. Para o acompanhamento da pesquisa foi aberto um transecto de $2500 \mathrm{~m}$, onde as árvores matrizes tidas como porta-sementes e detentoras de ótimas características fenotípicas, em fase reprodutiva, foram selecionadas aleatoriamente, e distribuídas entre si, pelo menos a uma distância de $50 \mathrm{~m}$ dentro do transecto.

\section{Floração}

\section{RESULTADOS E DISCUSSÃO}

Entre as espécies avaliadas observou-se que o período de floração foi distribuído principalmente no período seco e seco-chuvoso (quadro 1).

QUADRO 1: Floração das espécies estudadas no período de 28 meses no município de Porto Grande-AP.

\begin{tabular}{|l|c|c|c|}
\hline \multicolumn{1}{|c|}{ Espécies } & Período & Duração & Pico \\
\hline Carapa guianensis Aubl & seco/chuvoso & 5 meses & dez-fev \\
\hline Caryocar villosum (Aubl.) Pers. & Seco & 1 mês & out 97/ ago 99 \\
\hline Virola melinonii (Benoist) A.C. Sm & Seco & 2 meses & Agosto \\
\hline
\end{tabular}


A C. guianensis floresceu durante o período intermediário de precipitação (transição entre as estações seca e chuvosa) (Figura 1). A duração da fase de floração foi de cinco meses que ocorreu nos meses de outubro a fevereiro (Figura 1).

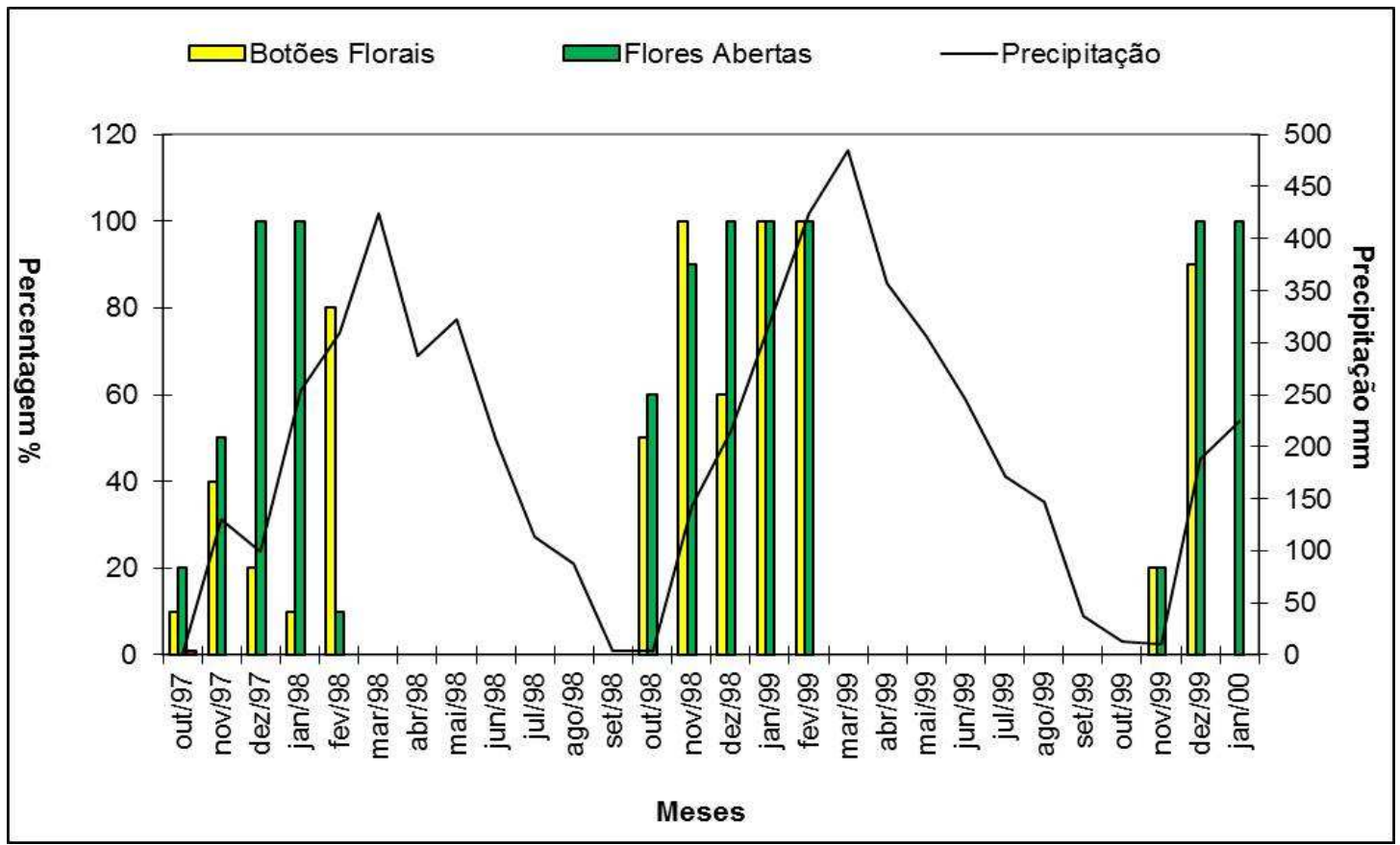

FIGURA 1: Floração da subpopulação da $C$. guianensis em relação à Fonte: Pesquisa de campo. precipitação no município de Porto Grande-AP.

A floração do $C$. villosum ocorreu no período seco em relação à precipitação no município de Porto Grande. A floração do primeiro ano de observação ocorreu no mês de outubro de 1997 e a segunda floração observada para espécie ocorreu em agosto de 1999 (Figura 2).

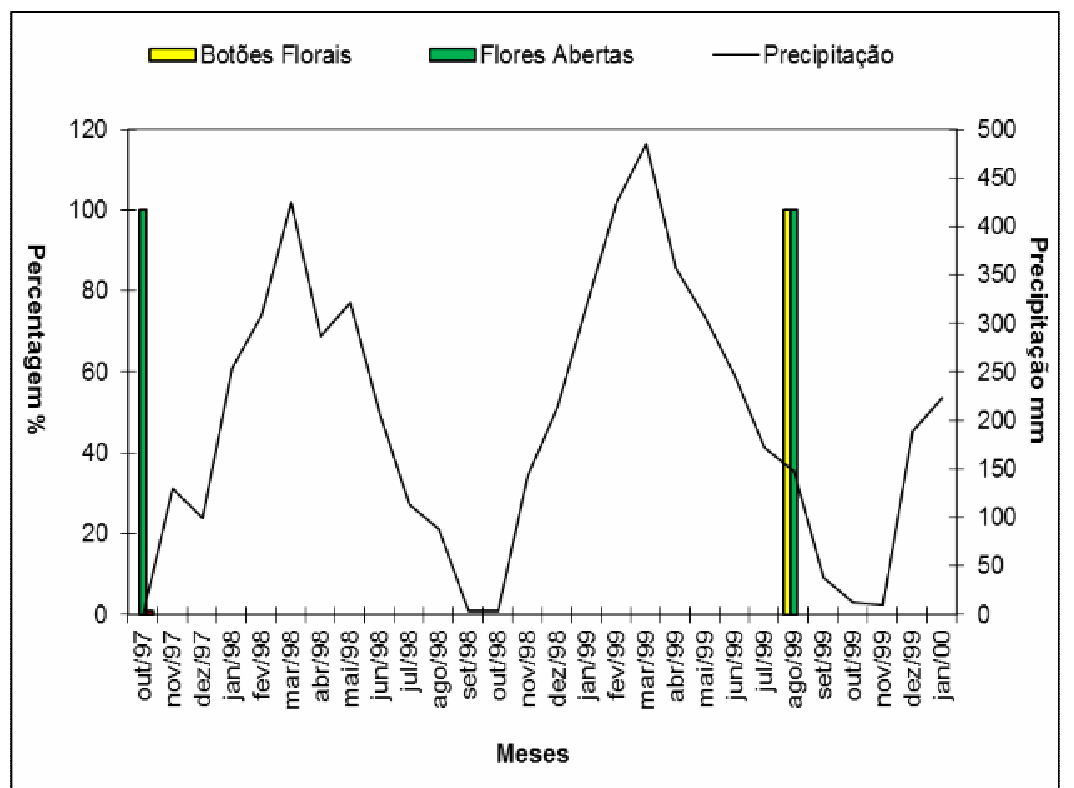

FIGURA 2: Floração da subpopulação da $C$. villosum em relação à precipitação no município de Porto Grande-AP. Fonte: Pesquisa de campo. 
A espécie $V$. melinonii floresceu no período com as menores taxas de precipitação (Figura 3). A duração da fase de floração, nos 28 meses de observação, apresentou uma pequena diferença em relação à primeira fase de floração registrada para a espécie. No primeiro ano, a $V$. melinonii floresceu durante quatro meses e no segundo ano durante apenas dois meses.

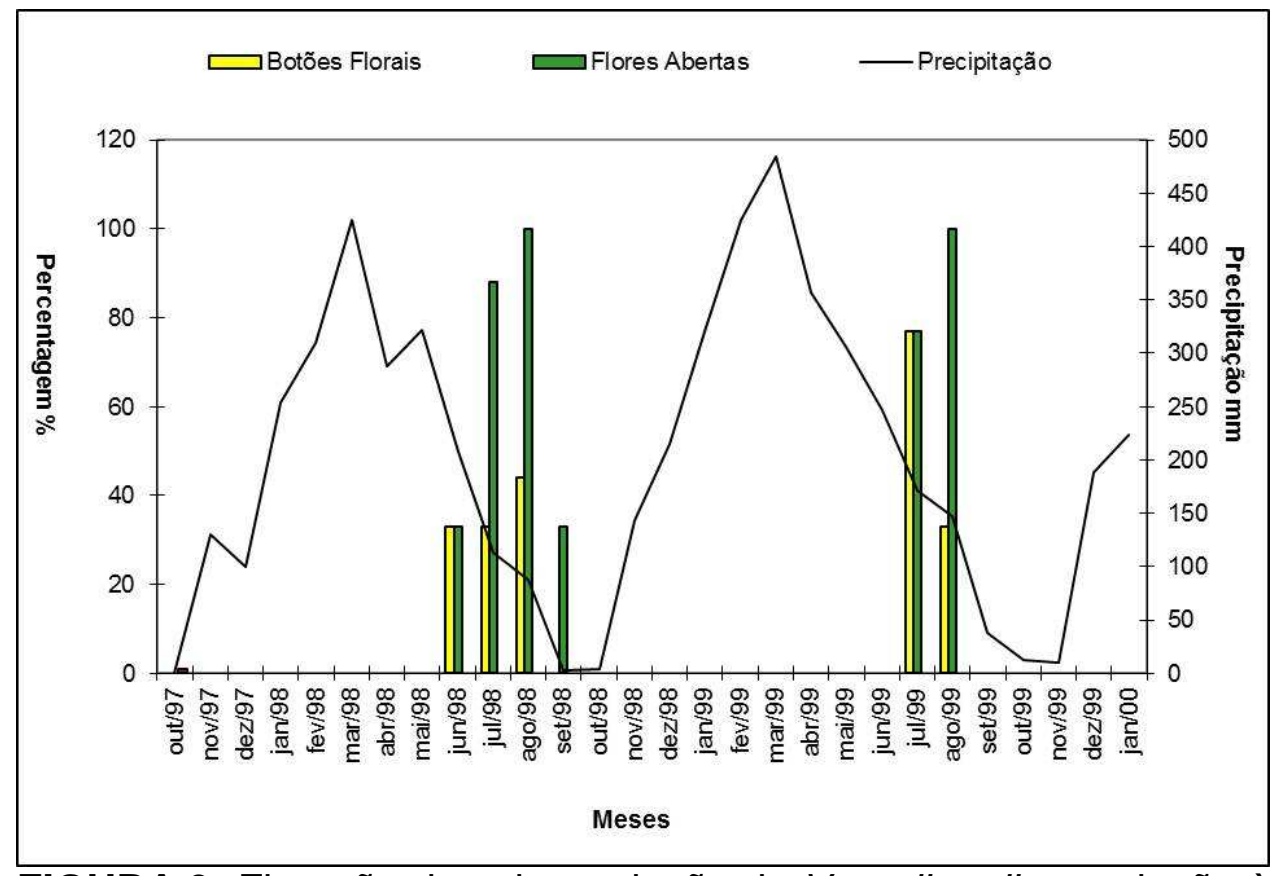

FIGURA 3: Floração da subpopulação da $V$. melinonii em relação à precipitação no município de Porto Grande-AP.

Fonte: Pesquisa de campo.

Ao analisar a variação da época de floração para diversas espécies arbóreas tropicais amazônicas e PINTO et al. (2008), COBRA et al. (2015) e FREITAS et al. (2015) relataram que a maioria das espécies estudadas floresce na época de seca, comportamento observado para as espécies nesse estudo.

O trabalho de PEREIRA \& TONINI (2012), demostrou que fenologia floral da C. guianensis teve uma duração de três meses que foi de dezembro a fevereiro. $O$ mesmo trabalho teve três anos de observação e o período de floração é similar ao estudado no município de Porto Grande-AP. De acordo com FREITAS et al. (2013), a C. guianensis, independentemente do ecossistema avaliado (terra firme ou várzea), apresenta preferência para florescer em períodos menos chuvosos, ou seja, abaixo dos $300 \mathrm{~mm}$ mensais.

Entre as espécies estudadas, C. villosum não apresentou um padrão de floração de um ano para outro. No trabalho de COBRA et al. (2015) a floração de Cordiera macrophylla em floresta estacional limitou-se a três meses do ano, durante a estação seca. No trabalho de PINTO et al. (2008) constatou-se que houve floração anual, mas sem regularidade no período de ocorrência que recaiu na estação secachuvosa. Em comunidades vegetacionais tropicais a floração contínua (na estação seca, chuvosa e em períodos de transição entre as estações) é fundamental, sobretudo para manutenção da diversidade da flora e fauna (VIEIRA et al., 2012). 


\section{FRUTIFICAÇÃO}

A fase de frutificação foi observada principalmente nos períodos secochuvoso e chuvoso (Quadro 2).

QUADRO 2: Frutificação das espécies estudadas no período de 28 meses no município de Porto Grande-AP.

\begin{tabular}{|l|l|l|c|}
\hline Espécie & Período & Duração & Pico \\
\hline Carapa guianensis & Chuvoso & 5 meses & mar-abr \\
\hline Caryocar villosum & seco-chuvoso & 8 meses & nov-mar \\
\hline Virola melinonii & seco-chuvoso & 6 meses & nov-jan \\
\hline
\end{tabular}

A frutificação da $C$. guianensis durante o estudo ocorreu entre os meses de janeiro a maio (Figura 4).

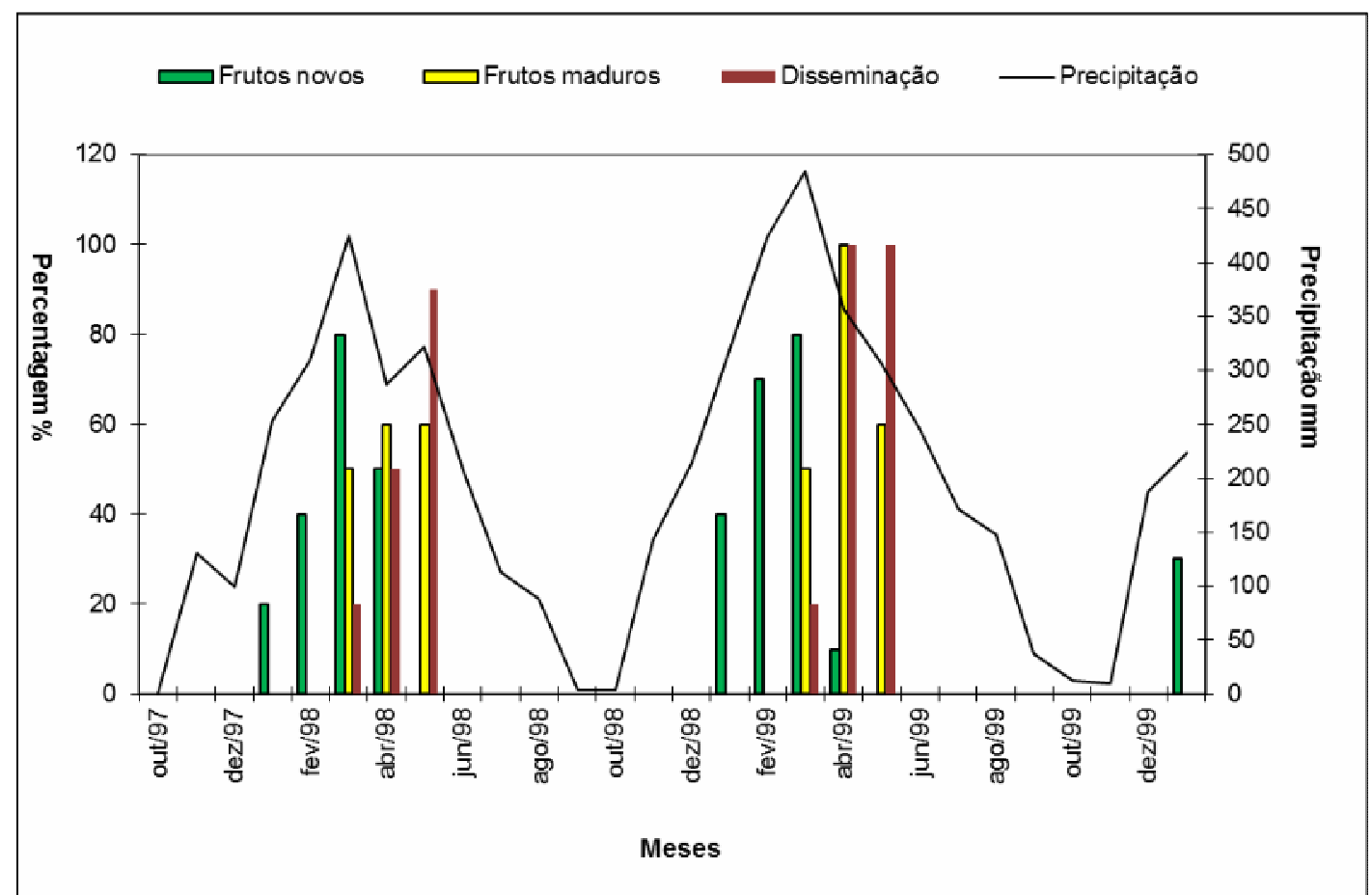

FIGURA 4: Frutificação da subpopulação da $C$. guianensis em relação à precipitação no município de Porto Grande-AP.

Fonte: Pesquisa de campo.

A espécie C. villosum frutificou no período chuvoso, porem só houve frutificação no primeiro ano de observação (Figura 5). 


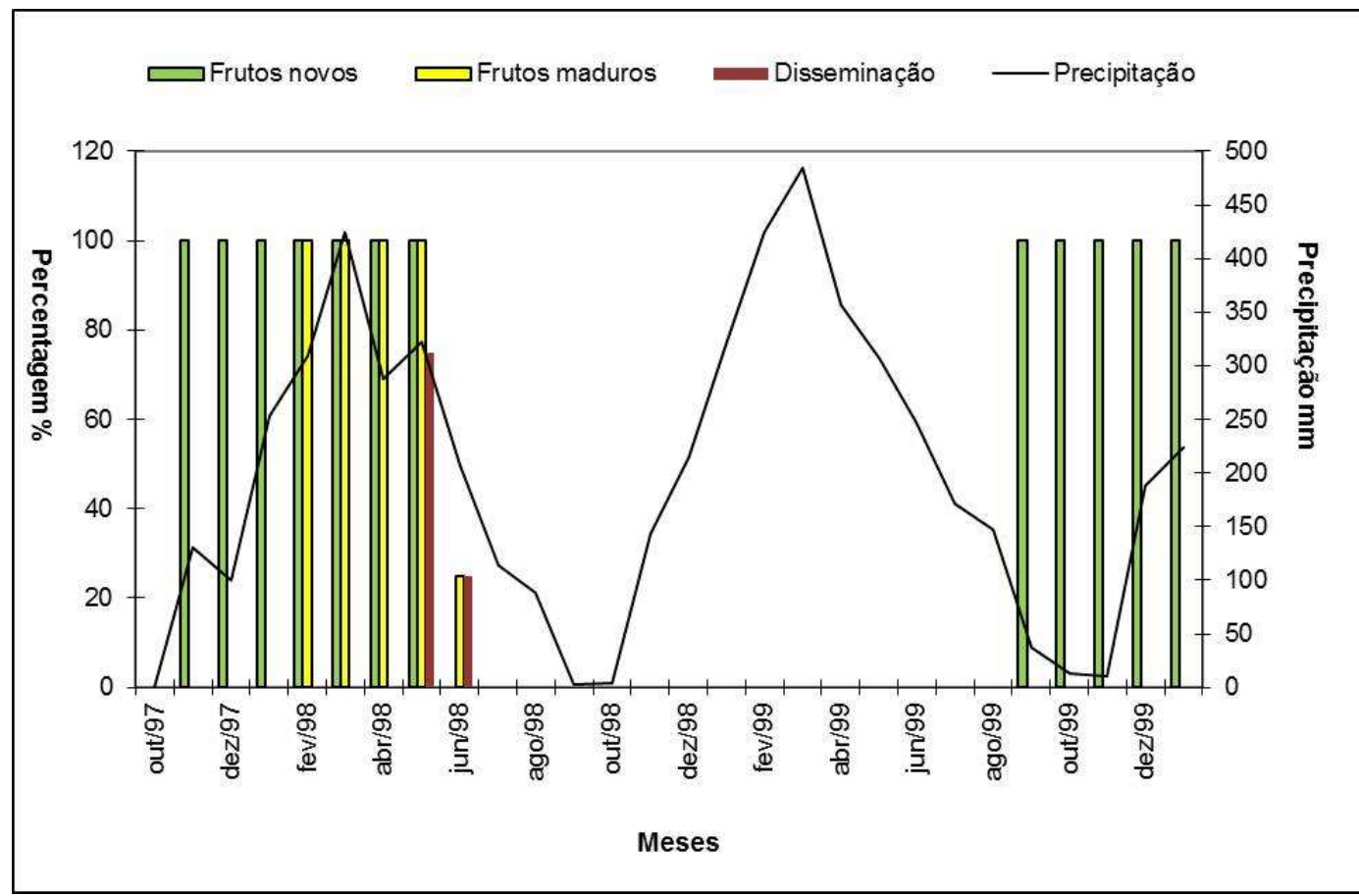

FIGURA 5: Frutificação da subpopulação da $C$. villosum em relação à precipitação no município de Porto Grande-AP.

Fonte: Pesquisa de campo.

A espécie $V$. melinonii teve incidência de frutificação entre os meses de outubro e janeiro como observado na Figura 6.

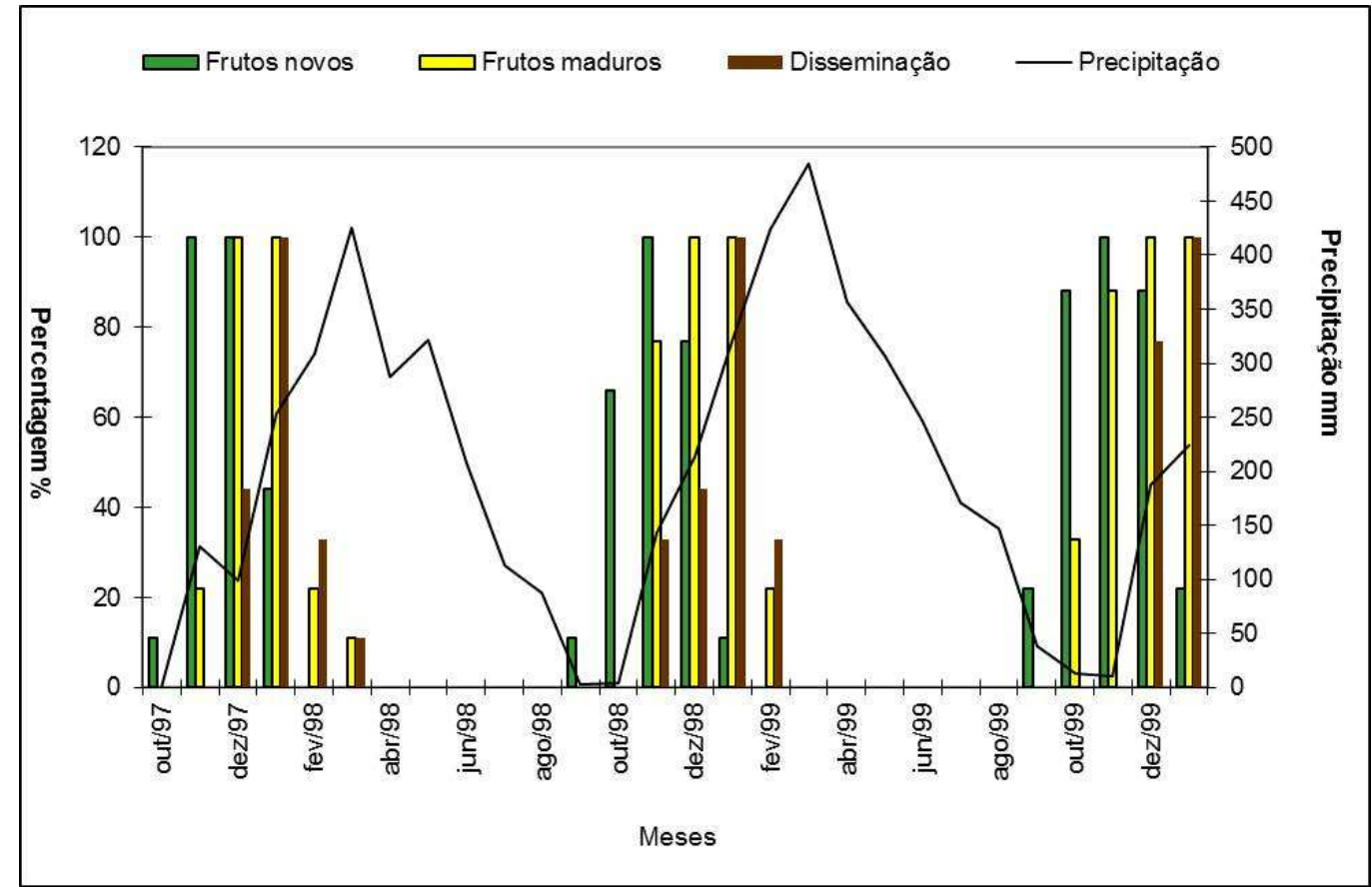

FIGURA 6: Frutificação da subpopulação da $V$. melinonii em relação à precipitação no município de Porto Grande-AP.

Fonte: Pesquisa de campo.

A frutificação da $C$. guianensis ocorreu com maior intensidade durante os meses de maior precipitação pluviométrica. De acordo com FREITAS et al. (2013) o 
pico da frutificação de Carapa guianensis, em ambos os ecossistemas (terra firme e várzea) ocorreu durante os meses de abril e maio, época de maiores índices de precipitação. De acordo com FERRAZ et al. (2002) um segundo período de frutificação foi observado nos meses de outubro e novembro, contudo a fenologia é muito variável, podendo ocorrer frutificação ao longo de todo o ano. A espécie $C$. villosum apresentou fenofase frutificação no início do período seco no final dos meses de observação. A fase de frutificação ocorreu principalmente durante a transição do período seco para o chuvoso.

A frutificação para espécie $V$. melinonii foi evidenciada nos períodos de transição entre a estação seca para estação chuvosa, o que mostra a influência da precipitação pluviométrica em relação aos padrões de frutificação da espécie. Em estudo sobre a fenologia do inajá, PIRES et al. (2016) identificaram a precipitação como sendo fator climático importante para a fenologia da espécie, afetando positivamente a queda de frutos maduros, funcionando como um veículo de dispersão natural dos frutos.

\section{MUDANÇA FOLIAR}

Ocorreu diferença no padrão vegetativo da mudança foliar das espécies estudadas (Quadro 3). As espécies durante o ano tiveram uma quantidade consideravelmente grande de folhas maduras, tendo o seu estoque renovado constantemente por folhas novas.

QUADRO 3: Padrão da mudança foliar das espécies estudadas no período de 28 meses no município de Porto Grande-AP.

\begin{tabular}{|l|l|l|l|l|}
\hline Espécie & Família & Padrão & Período & Duração \\
\hline C. guianensis & Meliaceae & Perenifólio & & \\
\hline V. melinonii & Myristicaceae & Perenifólio & & \\
\hline C. villosum & Caryocaraceae & Decíduo & Chuvoso & + ou - 4 meses \\
\hline
\end{tabular}

Folhas maduras foram observadas durante todo o período de estudo, com a presença de folhas novas prevalecendo sobre as folhas velhas. Durante todo o período de estudo ocorreu a emissão de folhas novas continuamente pela espécie V. melinonii (Figuras 7 e 8). 


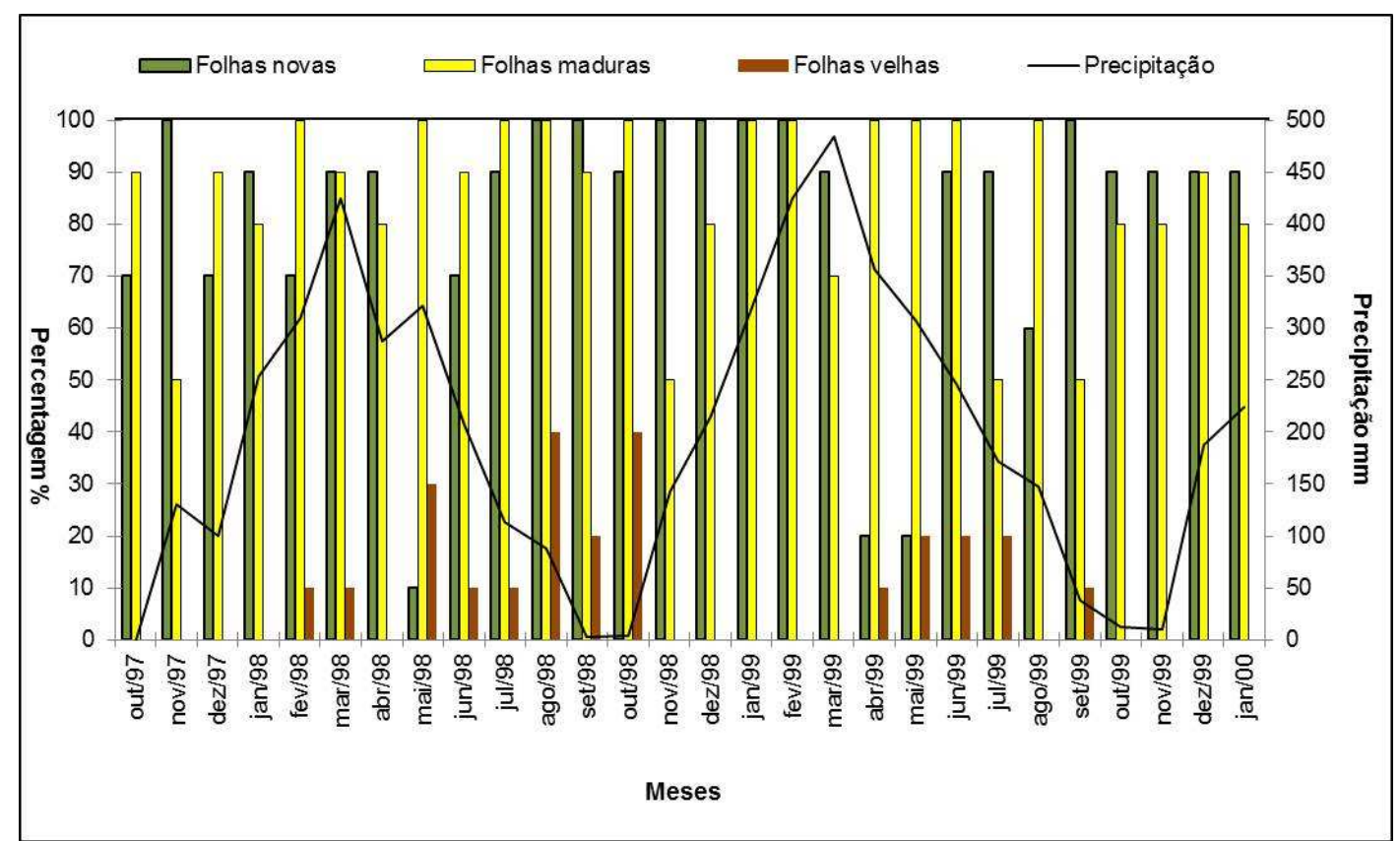

FIGURA 7: Padrão de mudança foliar da subpopulação da $C$. guianensis em relação à precipitação no município de Porto Grande-AP.

Fonte: Pesquisa de campo.

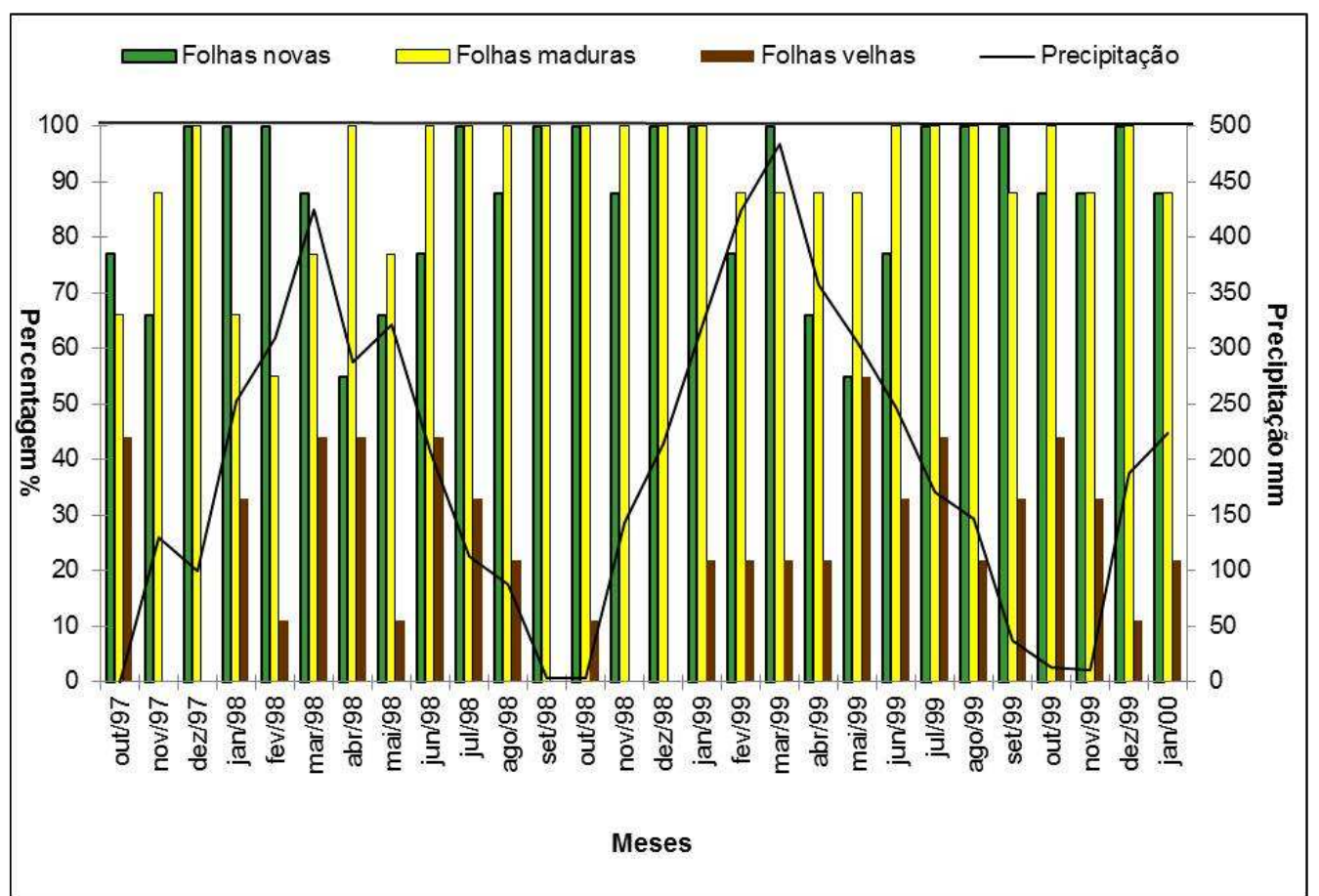

FIGURA 8: Padrão de mudança foliar da subpopulação da V. melinonii em relação à precipitação no município de Porto GrandeAP.

Fonte: Pesquisa de campo.

A espécie C. villosum teve uma época de fevereiro a maio de 1999 a perda total de suas folhas tendo características decíduas observadas somente naquele ano (Figura 9). 


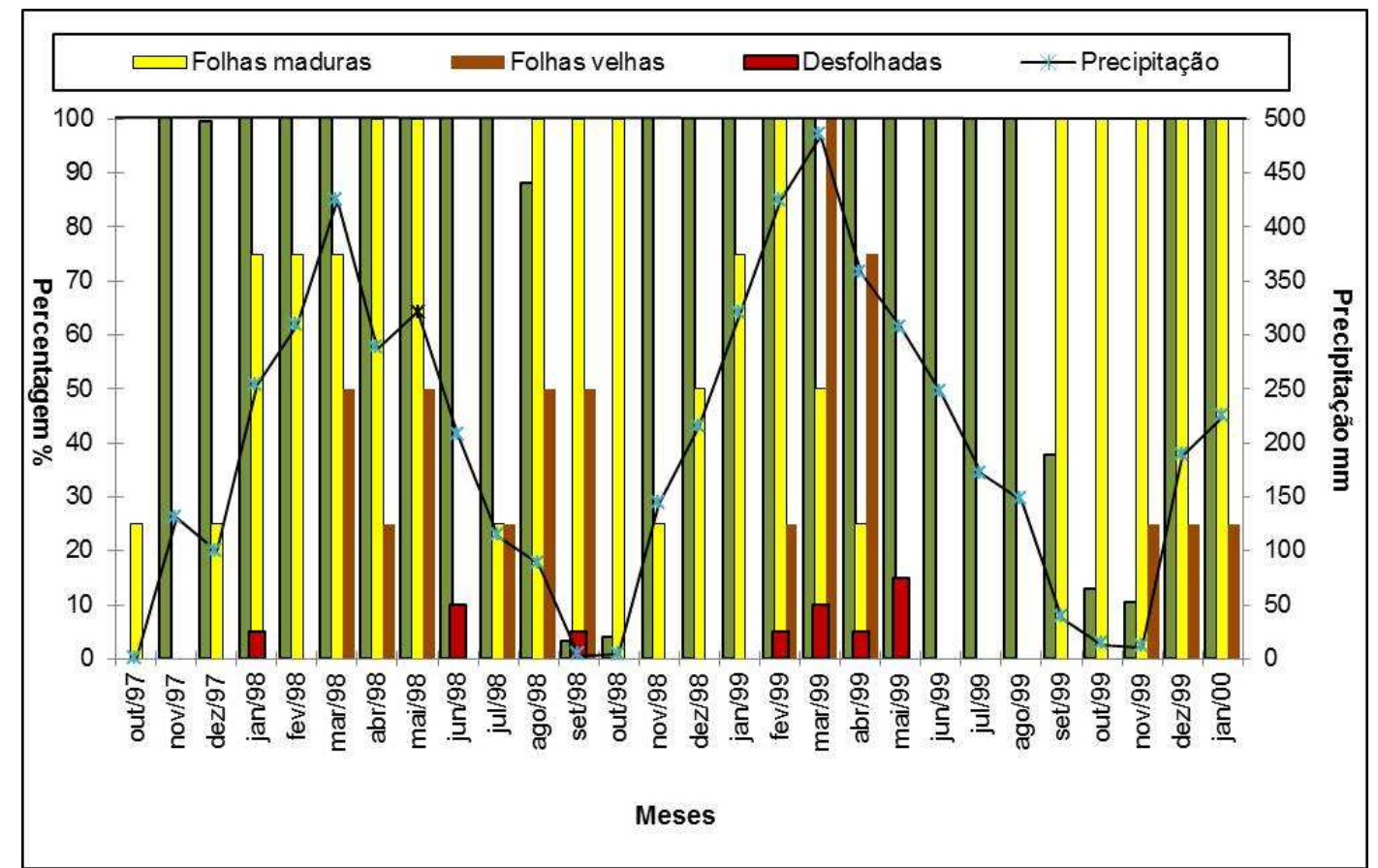

FIGURA 9: Padrão de mudança foliar da subpopulação da $C$. villosum em relação à precipitação no município de Porto Grande-AP.

Fonte: Pesquisa de campo.

A espécie $C$. guianensis evidenciou comportamento perenifólio para mudança de folhas, com queda e brotamento ao longo dos anos (FREITAS et al., 2013). PEREIRA \& TONINI (2012) também descreveram a espécie como perenifólia ao estudar o comportamento dessa espécie no sul de Roraima. Na região de Manaus, de acordo com FERRAZ et al. (2002) a espécie também apresentou padrão perenifólio para mudança foliar. Com relação à espécie $V$. melinonii algumas árvores desfolharam totalmente durante o período chuvoso, diferente do observado por VALENTINI et al. (2013) e SOUZA et al. (2014) que relataram queda total de folhas durante a estação seca. De modo geral, os padrões fenológicos das espécies apresentam diferentes sucessos e estratégias perante as distintas condições ambientais (LUCENA et al., 2015).

\section{CONCLUSÃO}

As espécies avaliadas apresentaram influência no padrão vegetativo e reprodutivo quando relacionadas com o regime pluviométrico;

As espécies $V$. melinonii, $C$. villosum tiveram a fenofase floração ocorrendo ou iniciando durante o período de estiagem na área de estudo;

O período mais adequado para a coleta de frutos de $C$. guianensis é entre os meses de abril e junho, para $C$. villosum é entre maio e junho, enquanto que, para $V$. melinonii o mais indicado é no mês de janeiro;

O padrão característico de mudança foliar encontrado para as espécies $C$. guianensis e C. villosum foi o perenifólio;

A espécie $C$. villosum sofreu queda total das folhas por quatro meses consecutivos, indicando padrão caducifólio.

\section{AGRADECIMENTOS}

Ao Instituto de Pesquisas Científicas e Tecnológicas do Estado do Amapá. 


\section{REFERÊNCIAS}

ABREU, J. C.; GUEDES, M. C.; GUEDES, A. C. L.; BATISTA, E. M. Estrutura e Distribuição espacial de Andirobeiras (Carapa Spp.) em floresta de várzea do Estuário Amazônico. Ciência Florestal, v. 24, n. 4, p. 1007-1016, 2014. Disponível em: <http://dx.doi.org/10.5902/1980509816614>. Doi: 10.5902/1980509816614

ATHAYDE, E. A.; GIEHL, E. L. H.; BUDKE, J. C.; GESING, J. P. A.; EISINGER, S. M. Fenologia de espécies arbóreas em uma floresta ribeirinha em Santa Maria, sul do Brasil. Revista Brasileira de Biociencias, v. 7, n. 1, p. 43-51, 2009. Disponível em: <http://www.ufrgs.br/seerbio/ojs/index.php/rbb/article/view/1050>

COBRA, S. S. O.; NASCIMENTO, F.; ANTONIAZZI, S. A.; KRAUSE, W.; SILVA, C. A. Biologia reprodutiva de Cordiera macrophylla (K. Schum.) Kuntze (Rubiaceae), espécie dioica da região sudoeste do Estado de Mato Grosso, Brasil. Revista Ceres, v. 62, n.6, p. 516-523, 2015. http://dx.doi.org/10. 1590/0034737X201562060002

FERRAZ, I. D. K.; CAMARGO, J. L. C.; SAMPAIO, P. T. B. Sementes e plântulas de Andiroba (Carapa guianensis AUBL. e Carapa procera D. C.): ASPECTOS BOTÂNICOS, ECOLÓGICOS E TECNOLÓGICOS. Acta Amazonica, v. 32, n. 4, p. 647-661, 2002. Disponível em: <http://dx.doi.org/1809-43922002324661>.Doi: 180943922002324661

FREITAS, J. L.; SANTOS, A. C.; SILVA, R. B. L.; RABELO, F. G.; SANTOS, E. S.; SILVA, T. L. S. Fenologia reprodutiva da espécie Carapa guianensis Aubl. (Andirobeira) em ecossistemas de terra firme e várzea, Amapá, Brasil. Biota Amazônia. Macapá, v. 3, p. 31-38, $2013 . \quad$ Disponível em:<http://dx.doi.org/10.18561/2179-5746/biotaamazonia.v3n1p31-38>.Doi: $10.18561 / 2179-5746$

FREITAS, J. L.; SILVA, R. B. L.; FILHO, M. N. B. F.; PATRICK DE CASTRO CANTUÁRIA, P. C.; JÚNIOR, F. O. C. Fenologia reprodutiva de cinco espécies arbóreas em ecossistema de terra firme na Amazônia Brasileira. Biota Amazônia, v. 5, n. 2, p. 38-44, 2015. Disponível em http://periodicos.unifap.br/index.php/biota.

FUNASAKI, M.; BARROSO, H. S.; VALDELIRA LIA ARAÚJO FERNANDES, V. L. A.; MENEZES, I. S. Amazon rainforest cosmetics: chemical approach for quality control. Quimica Nova, v. 39, n. 2, p. 194-209, 2016. Disponível em;. <http://dx.doi.org/10.5935/0100-4042.20160008>.doi: 10.5935/0100-4042.20160008

INSTITUTO NACIONAL DE METEOROLOGIA-INMET. Climas. Disponível em http://www.inmet.gov.br (Acessado em 15/09/16).

KUNZ, S. H.; IVANAUSKAS, N. M.; MARTINS, S. V.; SILVA, E.; STEFANELLO, D. Análise da Similaridade Florística Entre Florestas do Alto Rio Xingu, da Bacia Amazônica e do Planalto Central. Revista Brasileira de Botânica, v. 32, n. 4, p. 725 736, 2009. Disponível em: <http://dx.doi.org/10.1590/S010084042009000400011 >. Doi: 10.1590/S0100-84042009000400011 
LIEBSCH, D.; BOS MIKICH, S.. Fenologia reprodutiva de espécies vegetais da Floresta Ombrófila Mista do Paraná, Brasil. Revista Brasileira de Botânica, v. 32, n. 2, p. 375-391, 2009. Disponível em: <http://dx.doi.org/10.1590/S010084042009000200016>. Doi : 10.1590/S0100-84042009000200016

LUCENA, I. C., LEITE, M. B.; MATOS, D. M. S. A deciduidade foliar indica a vulnerabilidade de espécies lenhosas ao fogo. Revista Árvore, v. 39, n. 1, p. 59-68, 2015. Disponível em: http://www.scielo.br/pdf/rarv/v39n1/0100-6762-rarv-39-010059.pdf< http://dx.doi.org/10.1590/0100-67622015000100006>

MARTINS, R. L.; GRIBEL, R. Polinização de Caryocar villosum (Aubl.) Pers. (Caryocaraceae) uma árvore emergente da Amazônia Central. Revista Brasileira de Botânica, v. 30, n. 1, p. 37-45, 2007. Disponível em:<http://dx.doi.org/10.1590/S0100-84042007000100005>. Doi: $\quad 10.1590 / S 0100-$ 84042007000100005

MISSAGIA, C. C. C.; VERÇOZA, F. C., MARIA AliCE S. AlVES, M. A. S. A. Reproductive phenology and sharing of floral resource among hummingbirds (Trochilidae) in inflorescences of Dahlstedtia pinnata (Benth.) Malme. (Fabaceae) in the Atlantic forest. Anais da Academia Brasileira de Ciencias, v. 86 n. 4, p. 16931702, 2014. Disponível em: http://dx.doi.org/10.1590/0001-3765201420130134. Doi: 10.1590/0001-3765201420130134

NEVES, E. L.; FUNCH, L. S.; VAINA, B. F. Comportamento Fenológico de Três Espécies de Jatropha (Euphorbiaceae) da Caatinga, Semi-Árido do Brasil. Revista Brasileira de Botânica, v. 33, n. 1, p.155-166, 2010. Disponível em:< http://dx.doi.org/10.1590/S0100-84042010000100014>.doi:10.1590/S0100-

84042010000100014

OLIVEIRA, A. C. O.; PIEDADE, M. T. F. Implicações ecológicas da fenologia reprodutiva de Salix martiana Leyb. (Salicaceae) em áreas de várzea da Amazônia Central. Acta Amazonica, v. 32, n. 3, p. 377-385, 2002. Disponível em: <http://www.scielo.br/pdf/aa/v32n3/1809-4392-aa-32-3-0377.pdf>. Doi:10.1590/180943922002323385\#sthash.QoerTXmM.dpuf

PEREIRA, M. R. N.; TONINI, H. Fenologia da Andiroba (Carapa guianensis, Aubl., Meliaceae) No Sul do Estado de Roraima. Ciência Florestal, v. 22, n. 1, 2012. Disponível em:<http://dx.doi.org/10.5902/198050985078>. Doi: $10.5902 / 198050985078$

PINHEIRO, A. L. Fundamentos em taxonomia aplicados no desenvolvimento da dendrologia tropical. Viçosa, MG: Ed. UFV, 278p., 2014.

PINTO, A. M.; MORELLATO, L. P. C.; BARBOSA, A. P. Fenologia reprodutiva de Dipteryx odorata (Aubl.) Willd (Fabaceae) em duas áreas de floresta na Amazônia Central. Acta Amazonica, v. 38, n. 4, p. 643-650, 2008. Disponível em: < http://dx.doi.org/10.1590/S0044-59672008000400006>. Doi: 10.1590/S004459672008000400006 
PIRES, H. C. G.; ROSA, L. S. R.; CABRAL, B. S.; SILVA, V. M.; NOGUEIRA, G. A.; FERREIRA, P. R. N. F. Padrão Fenológico de Attalea maripa (Aubl.) Mart. em Áreas de Pastagens na Amazônia Oriental. Floresta e Ambiente, v. 23, n. 2, p. 170-179, 2016. Disponível em:<http://dx.doi.org/10.1590/2179-8087.048313>. Doi: $10.1590 / 2179-8087.048313$

SIST, P.; SABLAYROLLES, P.; BARTHELON, S.; SOUSA-OTA, L.; KIBLER, J. F.; RUSCHEL, A.; SANTOS, M. M.; EZZINE-DE-BLAS, D. The Contribution of Multiple Use Forest Management to Small Farmers Annual Incomes in the Eastern Amazon. Forests, v. 5, p. 1508-1531, 2014. Disponível em: <http://ainfo.cnptia.embrapa.br/digital/bitstream/item/104131/1/forests-05-01508v2.pdf>. Doi:10.3390/f5071508

SOUZA, D. R.; SOUZA, A. L. Emprego Do Método $B D q$ De Seleção Após A Exploração Florestal Em Floresta Ombrófila Densa De Terra Firme, Amazônia Oriental. Árvore, v. 29, n. 4, p. 617-625, 2005. Disponível em: < http://dx.doi.org/10.1590/S0100-67622005000400014>.Doi: $\quad 10.1590 / S 0100-$ 67622005000400014

SOUZA, D. N. N.; CAMACHO, R. G. V.; MELO, J. I. M.; ROCHA, L. N. G.; SILVA, N. F. S. Estudo fenológico de espécies arbóreas nativas em uma unidade de conservação de caatinga no Estado do Rio Grande do Norte, Brasil. Revista Biotemas, v. 27, n. 2, 2014. http://dx.doi.org/10.5007/2175-7925.2014v27n2p31.

VALENTINI, C. M. A.; ALMEIDA, J. D.; COELHO, M. F. B.; RODRÍGUEZ-ORTÍZ, C. E. Fenologia da siparuna guianensis Aublet em dois bosques de preservação ambiental em Cuiabá-MT. Cerne, Lavras, v. 19, n. 4, p. 581-591, 2013. Disponível em:<http://www.scielo.br/scielo.php?script=sci_arttext\&pid=S0104776020130004000 08>DOI: $10.1590 /$ S0104-77602013000400008

VIEIRA, M. F.; FONSECA, R. S.; ARAÚJO, L. M. Floração, polinização e sistemas reprodutivos em florestas tropicais. In: Ecologia de florestas tropicais do Brasil. Editora UFV, p. 53-84, 2012. 